\title{
Verification and Defined Dosage of Sodium Pentobarbital for a Urodynamic Study in the Possibility of Survival Experiments in Female Rat
}

\author{
Sheng-Fei Xu $\mathbb{D}^{1},{ }^{1}$ Guang-Hui Du $\mathbb{D}^{1},{ }^{1}$ Kuerbanjiang Abulikim, ${ }^{1}$ Peng Cao, ${ }^{1}$ \\ and Hui-bing Tan ${ }^{2}{ }^{2}$ \\ ${ }^{1}$ Department of Urology, Tongji Hospital, Tongji Medical College, Huazhong University of Science and Technology, Wuhan, \\ Hubei Province, China \\ ${ }^{2}$ Department of Anatomy, Jinzhou Medical University, Jinzhou, Liaoning Province, China \\ Correspondence should be addressed to Guang-Hui Du; ghdu@tjh.tjmu.edu.cn
}

Received 29 March 2020; Revised 24 May 2020; Accepted 30 May 2020; Published 12 June 2020

Academic Editor: Abdelwahab Omri

Copyright (C) 2020 Sheng-Fei Xu et al. This is an open access article distributed under the Creative Commons Attribution License, which permits unrestricted use, distribution, and reproduction in any medium, provided the original work is properly cited.

\begin{abstract}
Objectives. To evaluate the effects of pentobarbital dosages on lower urinary tract function and to define an appropriate dosage of sodium pentobarbital that would be suitable for urodynamic studies in which recovery from anesthesia and long term survive were needed for subsequent experiment. Methods. Twenty-four 8-week-old, female, virgin, Sprague-Dawley rats (200-250 g) were used in this study. Rats in study groups received gradient doses of pentobarbital intraperitoneally, and those in the control group received urethane intraperitoneally. External urethral sphincter electromyography (EUS-EMG) was recorded simultaneously during cystometry and leak point pressure tests. The toe-pinch reflex was used to determine the level of anesthesia. Results. Micturition was normally induced in both the urethane group and $32 \mathrm{mg} / \mathrm{kg}$ pentobarbital group. However, in groups of $40 \mathrm{mg} / \mathrm{kg}$ or $36 \mathrm{mg} / \mathrm{kg}$ pentobarbital, micturition failed to be induced; instead, nonvoiding contractions accompanied by EUS-EMG tonic activity were observed. There were no significant differences in leak point pressure or EUS-EMG amplitude or frequency between the urethane and $32 \mathrm{mg} / \mathrm{kg}$ pentobarbital groups. Conclusions. This study confirmed significant dose-dependent effects of pentobarbital on lower urinary tract function and $32 \mathrm{mg} / \mathrm{kg}$ pentobarbital as an appropriate dosage for recovery urodynamic testing, which enable the achievement of expected essential micturition under satisfactory anesthesia in female rats.
\end{abstract}

\section{Introduction}

Anesthesia is a necessary procedure for most urodynamic studies of lab animals, although the fully awake animals have been assessed in some urodynamic tests [1,2]. The optimal anesthetic procedure is the one that results in minimal impact on urodynamic parameters while providing satisfactory anesthetic conditions. Additionally, some urodynamic studies are necessarily performed in the awake animals of recovery from anesthesia and survive for a certain period of time for subsequent experiments [3]. Afferent neurotransmission from the periphery to supraspinal sensory centers is unaffected by urethane anesthesia. Therefore, urethane has become accepted as a preferred anesthetic for urodynamic studies due to its mild effects on the micturition in rats [4,
5]. However, due to its potential toxicity to both investigators and lab animals, the use of urethane is under strict regulation in some countries, and it is not recommended for recovery experiments due to high mortality after anesthesia; thus, it is only suitable for nonsurvival experiments in rats [6-10].

Sodium pentobarbital, a short-acting $\mathrm{GABA}_{\mathrm{A}}$-receptor potentiator [11], is a reliable anesthetic for survival experiments, which is often used in urodynamic studies [4, 9, 12-28]. However, pentobarbital can abolish the micturition in some cases [12, 29, 30]. In 1986, Yaksh and colleagues reported that the administration of sodium pentobarbital produced a complete blockade of the volume-evoked micturition reflex [12]. In 1987, Malmgren et al. also reported that no micturition occurred during cystometry conducted during pentobarbital anesthesia [29]. In the above studies, 
the dosage of sodium pentobarbital was $50 \mathrm{mg} / \mathrm{kg}$. By referring to the literature about anesthesia and surgery of laboratory animals, we noted that the suggested dosage of sodium pentobarbital for intraperitoneal injection was 30$40 \mathrm{mg} / \mathrm{kg}$ in rats $[31,32]$. There were remarkable differences in the dosages of pentobarbital between the recommended dosage and the dosage used in those studies reporting micturition blockage.

The previous studies have shown that the pentobarbital produced a dose-dependent inhibition of heart rate, blood pressure, and respiration [33, 34]. Similarly, the GABA receptor agonists produced a dose-dependent inhibition of micturition, with micturition inhibited only in high doses [35]. Although it has been well known that high-dose pentobarbital depresses micturition in rats $[12,29]$, up to now, the detail and precise effects of low-dose pentobarbital $(40 \mathrm{mg} / \mathrm{kg}$ or less) on micturition remain unclear in rats. To answer these questions and to define an appropriate dosage of sodium pentobarbital for urodynamic studies, we conducted the present study in female rats to investigate the dosedependent effect of pentobarbital on lower urinary tract function, with urethane anesthesia as a positive control.

\section{Materials and Methods}

2.1. Ethics Statement. All procedures involving animals were conducted in accordance with the guidelines of the Chinese Council on Animal Care and with approval from the Committees on Animal Experiments at Tongji Hospital (Tongji Medical College, Huazhong University of Science and Technology, Wuhan, China). All rats were housed in separated cages in a temperature-controlled room with a $12 \mathrm{~h}$ light/dark cycle and free access to food and water. All surgeries were performed under anesthesia, and all efforts were made to minimize animal suffering.

2.2. Animals and Experimental Design. Twenty-four 8-weekold, female, virgin, Sprague-Dawley rats (200-250 g) were used in this study. Rats were divided into 4 groups: the control group received urethane $(1.2 \mathrm{~g} / \mathrm{kg})$ intraperitoneally (i.p., $n=6)$ [36]; the other 3 groups received graded doses of sodium pentobarbital intraperitoneally at $32(n=6), 36$ $(n=6)$, and $40(n=6) \mathrm{mg} / \mathrm{kg}$. The toe-pinch reflex was used to determine the level of anesthesia in the present study [37].

2.3. Surgical Preparation. Anesthesia was induced with 3.5\% isoflurane in oxygen, and surgery was carried out at $2.5 \%$ isoflurane in oxygen. A midline abdominal incision was made to expose the bladder under a microscope. A $15 \mathrm{~cm}$ length polyethylene catheter (PE-50) with a flared tip (inner diameter: $0.58 \mathrm{~mm}$, outer diameter: $0.96 \mathrm{~mm}$ ) was inserted into the bladder dome to measure intravesical pressure of the bladder, and a purse-string suture was used to close the bladder dome incision tightly. The rest of the catheter was tunneled subcutaneously and secured with a hitch suture to the rectus fascia and lower abdominal skin to prevent slippage. The pubic symphysis and the medial portion of the pubic bones were removed to expose the mid portion of the urethra. When preparatory surgery was completed, the isoflurane anesthesia was turned off. Thereafter, an intraperitoneal injection of sodium pentobarbital or urethane was administered for subsequent urodynamic measurements.

2.4. Filling Cystometry with Simultaneous External Urethral Sphincter Electromyography (EUS-EMG) Recordings. For cystometry, the opposite end of the bladder catheter was attached to a 3-way connector connected to both a programmable infusion pump and a pressure transducer to support bladder infusion and bladder pressure recordings, respectively. For recording EUS-EMG activity, a parallel bipolar electrode was placed on the surface of the EUS bilaterally at the midurethra. CMG and EUS-EMG data were amplified and digitized using a multiple channel electrophysiological recording system (PowerLab 26T, AD Instruments, Australia). The perfusion speed was set to $0.1 \mathrm{ml} / \mathrm{min}$ (Figure 1). The cystometry signal was recorded at $1 \mathrm{kHz}$ and low-pass filtered at 100 $\mathrm{HZ}$, and the EMG signal was recorded at $6 \mathrm{kHz}$ with band pass frequencies from $20 \mathrm{~Hz}$ to $3 \mathrm{kHz}$. The segment of the EMG was filtered for $60 \mathrm{~Hz}$ noise (power supply frequency). A total of 3-4 consecutive voiding cycles were collected. The intercontraction interval (ICI), pressure threshold $(\mathrm{PT})$, resting pressure (RP), maximum intravesical pressure (MIVP), contraction duration (CD), expulsion time (ET), and bursting activity period (BP) were determined according to established criteria $[38,39]$.

2.5. Leak Point Pressure (LPP) with Simultaneous EUS-EMG Recordings. LPP recordings were performed after cystometry determinations. For LPP testing, the bladder was filled to half capacity [40]. An external increase in bladder pressure was made by slowly pressing on the bladder using a cotton swab and removing it quickly at the first sign of fluid leakage at the urethral meatus. A mean of 4 LPP tests was performed in each animal, and a mean of the results was calculated and used. LPP was calculated as baseline pressure subtracted from peak pressure [41]. EUS-EMG activity at baseline and at the peak pressure of the LPP test was analyzed in three or four 1-second samples, as previously described [36].

2.6. Statistical Analysis. The values for each parameter were averaged for each rat, and the quantitative data were expressed as the means \pm standard error (SE). EUS-EMG analysis using Matlab software. Data of EUS-EMG and LPP were compared using one-way analysis of variance (ANOVA). The filling cystometry data obtained in the urethane- and $32 \mathrm{mg} / \mathrm{kg}$ pentobarbital-anesthetized groups were compared statistically using Student's $t$-test. We regarded a $P$ value of less than 0.05 to indicate a statistically significant difference between groups.

\section{Results}

3.1. Micturition. In all rats that received $32 \mathrm{mg} / \mathrm{kg}$ pentobarbital and urethane anesthesia, the micturition could be observed, and all rats could be kept quiet during bladder filling (Figure 2). However, in all rats anesthetized with $40 \mathrm{mg} / \mathrm{kg}$ and $36 \mathrm{mg} / \mathrm{kg}$ pentobarbital, no micturition could be evoked instead of nonvoiding contractions, with all rats keeping quiet during bladder filling (Figure 3). The mean duration of the loss of the micturition was a significant 


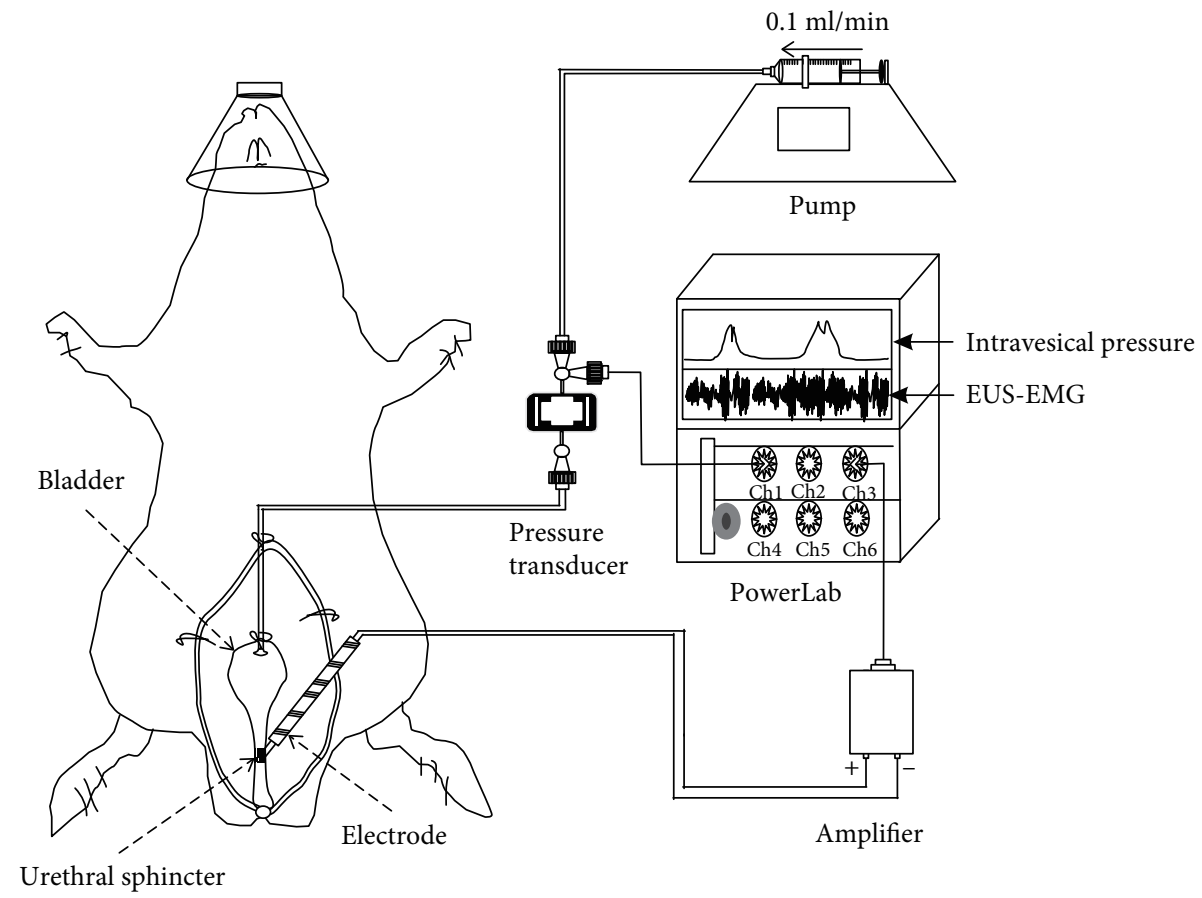

FIGURE 1: Schematic of cystometry with simultaneous external urethral sphincter electromyography recording in rat. EUS-EMG: external urethral sphincter electromyography; Ch: channel.

difference between the control group and the group of $32 \mathrm{mg} / \mathrm{kg}$ pentobarbital anesthesia, which amounted to 51.67 \pm 4.63 and $78.75 \pm 4.15$ minutes, respectively $(p<0.05)$. However, in rats that received 40 and $36 \mathrm{mg} / \mathrm{kg}$ pentobarbital, micturition was suppressed for more than 3 hours. The toe-pinch reflex was negative in all study groups.

3.2. EUS-EMG. In all rats that received $32 \mathrm{mg} / \mathrm{kg}$ pentobarbital and urethane anesthesia, the tonic EUS-EMG activity slowly increased during bladder filling and closely matched the rise in intravesical pressure at the onset of bladder contractions. During the voiding phase, the EUS-EMG changed from tonic activity to bursting activity. After voiding, the intravesical pressure returned to baseline, and the bursting EUS-EMG activity shifted to a tonic pattern again (Figure 2).

In rats that received 40 and $36 \mathrm{mg} / \mathrm{kg}$ pentobarbital, the micturition disappeared and was replaced by nonvoiding contractions. Each nonvoiding contraction corresponded to increased tonic activity of EUS-EMG. Leakage occurred subsequent to bladder filling and was accompanied by increased tonic activity of the external urethral sphincter, but largeamplitude EUS-EMG bursting activity and large-amplitude reflex bladder contractions were eliminated (Figure 3).

3.3. Cystometric Parameters. For a more detailed assessment of the two anesthetic agents on the contractile properties of the bladder, we compared the parameters of cystometry in rats that received $32 \mathrm{mg} / \mathrm{kg}$ pentobarbital anesthesia with those in rats of the urethane group. There were significant differences in CD and BP between the two groups. However, no significant differences in ICI, PT, RP, MIVP, and ET were observed (Figure 4).
3.4. LPP Testing. No significant differences in LPP were observed among the four groups. In all rats that received $32 \mathrm{mg} / \mathrm{kg}$ pentobarbital and urethane anesthesia, no significant differences in EUS-EMG frequency and amplitude were observed (Figure 5).

\section{Discussion}

It is well known that GABA can inhibit reflex-activated bladder motility by acting though different distinct sites [35]. Sodium pentobarbital, a short-acting $\mathrm{GABA}_{\mathrm{A}}$-receptor potentiator [11], enhances inhibition mediated by $\mathrm{GABA}_{\mathrm{A}}$, increasing the average burst duration of activated $\mathrm{GABA}_{\mathrm{A}}$ receptor channels [42], which may be one of the mechanisms of pentobarbital inhibiting lower urinary tract function. In a previous study, the doses of sodium pentobarbital intraperitoneal injection were administrated from $30 \mathrm{mg} / \mathrm{kg}$ to $60 \mathrm{mg} / \mathrm{kg}$ of body weight in rat for urodynamic experiments $[12,17,23$, 26, 28, 43]. However, high dose inhibits micturition and causes higher mortality for recovery experiments [12, 29, 30]. In the present study, we defined the precise effects of gradient dosages of sodium pentobarbital on micturition. In rats that received $40 \mathrm{mg} / \mathrm{kg}$ and $36 \mathrm{mg} / \mathrm{kg}$ sodium pentobarbital, the micturition could not be maintained, which is consistent with previous studies $[12,29]$, while in rats that received $32 \mathrm{mg} / \mathrm{kg}$ pentobarbital, the micturition could be induced in all rats. Additionally, the toe-pinch reflex was negative in all groups of rats during urodynamic recording, which is indicative of a satisfactory level of anesthesia.

In 2000, Matsuura and Downie [4] reported that the micturition was suppressed under pentobarbital at 30$50 \mathrm{mg} / \mathrm{kg}$ (i.p.). The possible explanation is that there were two questionable debates in the experimental method 


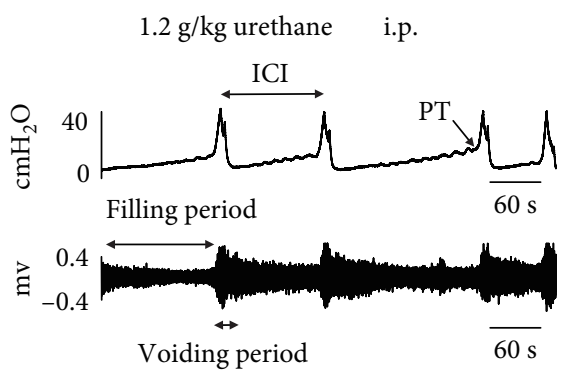

(a)
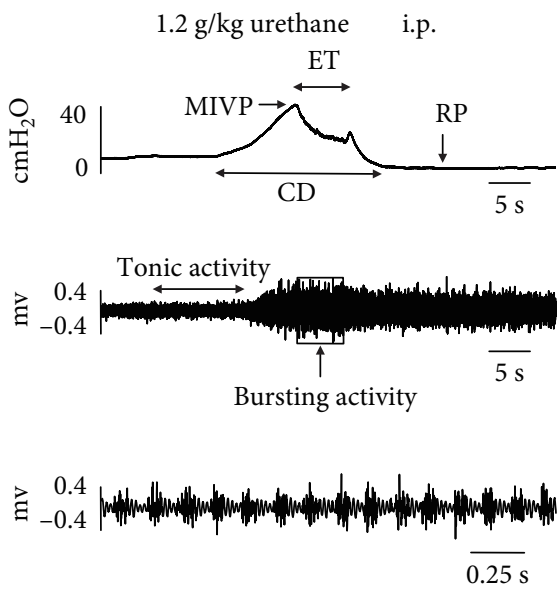

(c)

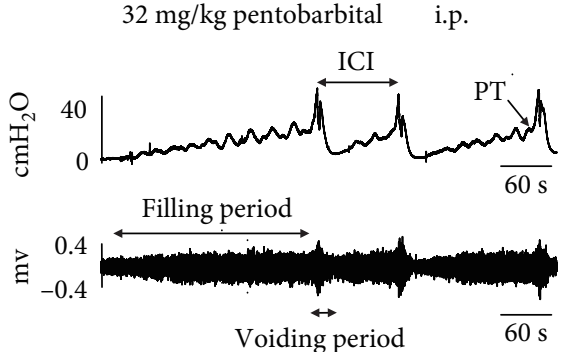

(b)
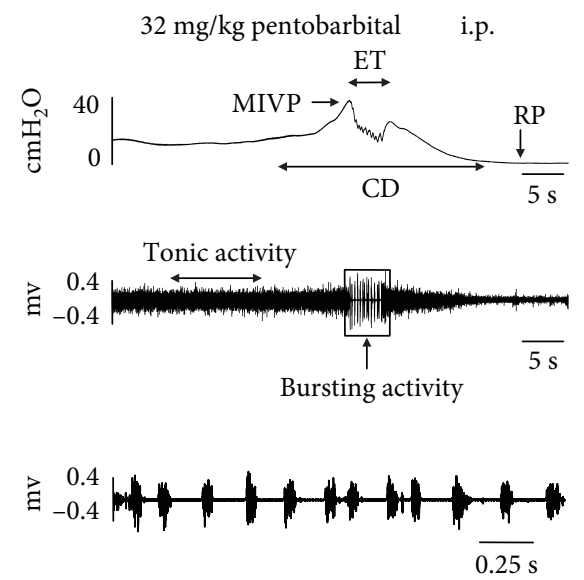

(d)

FIgURe 2: Typical examples of cystometry under anesthesia with urethane and $32 \mathrm{mg} / \mathrm{kg}$ sodium pentobarbital. Micturition could be observed in the urethane group (a) and $32 \mathrm{mg} / \mathrm{kg}$ pentobarbital group (b). (c) and (d) shows tonic EUS-EMG activity shifted to a bursting pattern at the peak of the bladder contraction in the urethane and $32 \mathrm{mg} / \mathrm{kg}$ pentobarbital groups. Top, cystometrogram; middle, EUS-EMG activity during filling and voiding; bottom, EUS bursting activity during voiding in faster time phase. EUS-EMG: external urethral sphincter electromyography; ICI: intercontraction interval; PT: pressure threshold; RP: resting pressure; MIVP: maximum intravesical pressure; CD: contraction duration; ET: expulsion time; i.p.: intraperitoneal injection.

reported by Matsuura and Downie [4], which led to their results being inaccurate. First, their study only described that the dose of sodium pentobarbital in the experiment was 30$50 \mathrm{mg} / \mathrm{kg}$, but the study lacked detailed evaluation of the effect of different doses of sodium pentobarbital on micturition. Second, the sample size of the study was small and only 4 rats were studied. From experimental methodology, we found that animals were not studied in groups. Therefore, the results of this experiment cannot conclude that intraperitoneal injection of sodium pentobarbital at low dose (40 mg/kg or less) can inhibit micturition. However, to our knowledge, we are the first to use serial decrement doses of sodium pentobarbital to evaluate the effects of low-dose pentobarbital $(40 \mathrm{mg} / \mathrm{kg}$ or less) on micturition in female rats. Our evidence showed that, among these doses of sodium pentobarbital, only $32 \mathrm{mg} / \mathrm{kg}$ sodium pentobarbital can sparely be available for the micturition. Additionally, in our recent studies, it was shown that micturition was suppressed for $78.75 \pm 4.15$ minutes after anesthesia with $32 \mathrm{mg} / \mathrm{kg}$ pentobarbital, which is in line with a previous study [9]. The study showed that pentobarbital can cause the micturition to disappear for a long time (60-90 minutes). However, there was an anesthesia window allowing for micturition reflex studies for more than an hour [9].
In the present study, our results still suggested that the ICI in the pentobarbital group $(32 \mathrm{mg} / \mathrm{kg})$ was longer than that in the urethane group, although no significant difference was observed. Such prolongation of the ICI may imply an increased bladder capacity [39]. Furthermore, a shortened $\mathrm{BP}$ in the $32 \mathrm{mg} / \mathrm{kg}$ pentobarbital group was observed compared with that in the urethane group. The shorter BP may reduce efficient bladder emptying, although a longer CD was observed compared with the urethane group. This effect of anesthetic on cystometry should be taken into consideration when cystometry is anesthetized with pentobarbital at a dosage of $32 \mathrm{mg} / \mathrm{kg}$.

Previous studies reported that EUS bursting is a critical event and necessary for efficient bladder emptying [44, 45]. When $40 \mathrm{mg} / \mathrm{kg}$ and $36 \mathrm{mg} / \mathrm{kg}$ pentobarbital were administered, the external urethral sphincter showed an increased tonic activity without a large-amplitude EUS-EMG bursting activity, which was similar with detrusor sphincter dyssynergia, and cannot produce efficient voiding. However, in the $32 \mathrm{mg} / \mathrm{kg}$ pentobarbital, the EUS-EMG changes from tonic activity to bursting activity during the voiding phase. After voiding, the bursting EUS-EMG activity shifts to a tonic pattern again. These characteristics of EMG are similar with those with urethane anesthesia. 


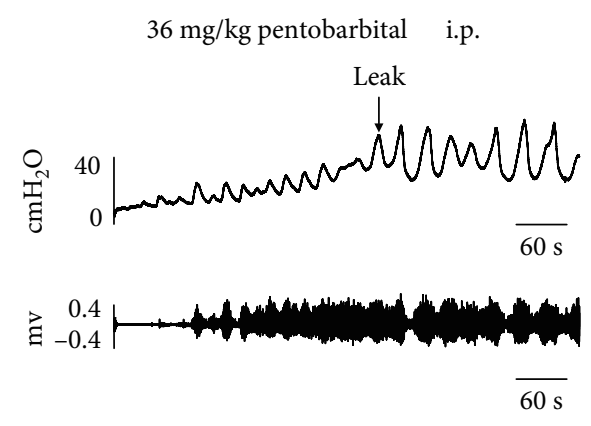

(a)

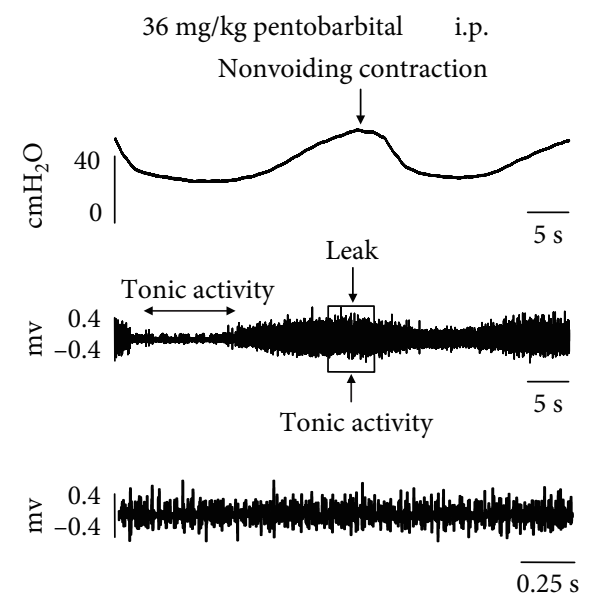

(c)
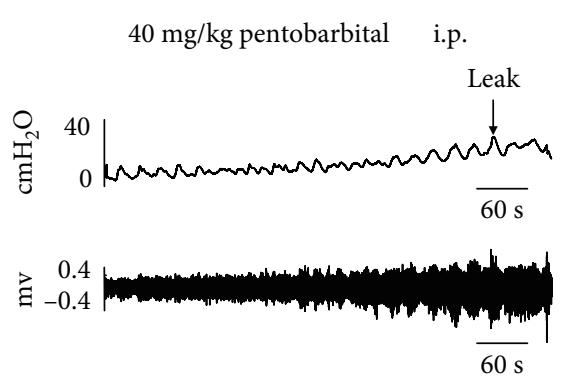

(b)

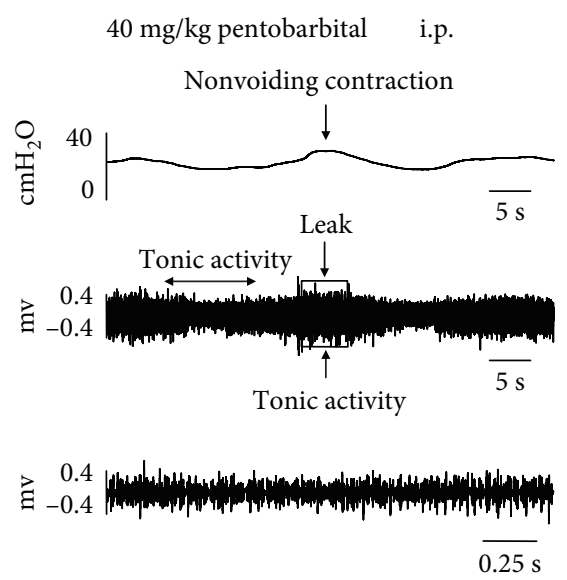

(d)

Figure 3: Typical examples of cystometry under anesthesia with 36 and $40 \mathrm{mg} / \mathrm{kg}$ sodium pentobarbital. Micturition could not be observed in the $36 \mathrm{mg} / \mathrm{kg}$ group (a) and $40 \mathrm{mg} / \mathrm{kg}$ pentobarbital group (b). (c) and (d) shows increased tonic EUS-EMG activity during a nonvoiding contraction with a bladder leak response in the $36 \mathrm{mg} / \mathrm{kg}$ and $40 \mathrm{mg} / \mathrm{kg}$ pentobarbital groups. Top, cystometrogram; middle, EUS-EMG activity during filling and nonvoiding contraction; bottom, EUS bursting activity during nonvoiding contraction in faster time phase. EUS-EMG: external urethral sphincter electromyography; i.p.: intraperitoneal injection.

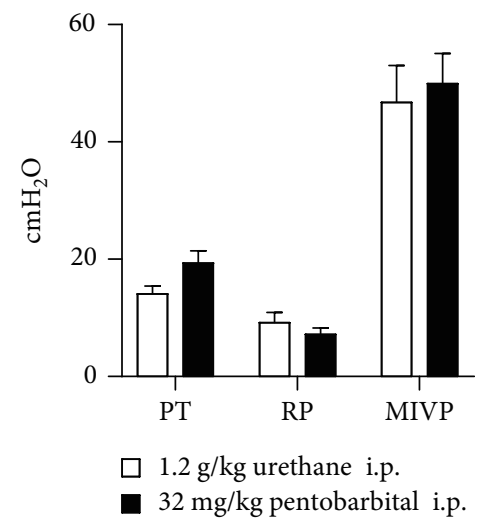

(a)

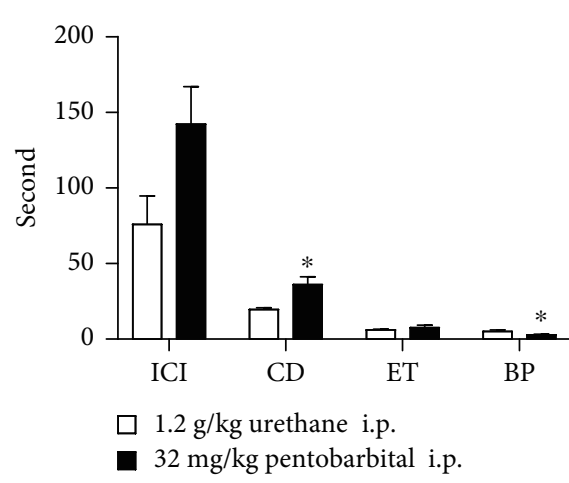

(b)

Figure 4: Parameters of cystometry results under anesthesia with urethane and $32 \mathrm{mg} / \mathrm{kg}$ sodium pentobarbital. Data reported as the mean \pm SEM. PT: pressure threshold; RP: resting pressure; MIVP: maximum intravesical pressure; ICI: intercontraction interval; CD: contraction duration; ET: expulsion time; BP: bursting activity period; i.p.: intraperitoneal injection. ${ }^{*} p<0.05$.

The bladder-to-urethral reflex has been proved to be an important role in the prevention of urinary leakage [46]. When a passive external pressure is applied to the bladder (LPP), the EUS-EMG activity is increased to elevate the urethral resistance. In the present study, rats that received
$40 \mathrm{mg} / \mathrm{kg}, 36 \mathrm{mg} / \mathrm{kg}$, and $32 \mathrm{mg} / \mathrm{kg}$ sodium pentobarbital demonstrated typical LPP and EUS-EMG data with a statistically significant increase in EUS-EMG frequency during LPP testing, considering that the bladder-to-urethral reflex also exists in female rats by pentobarbital anesthesia. In the 

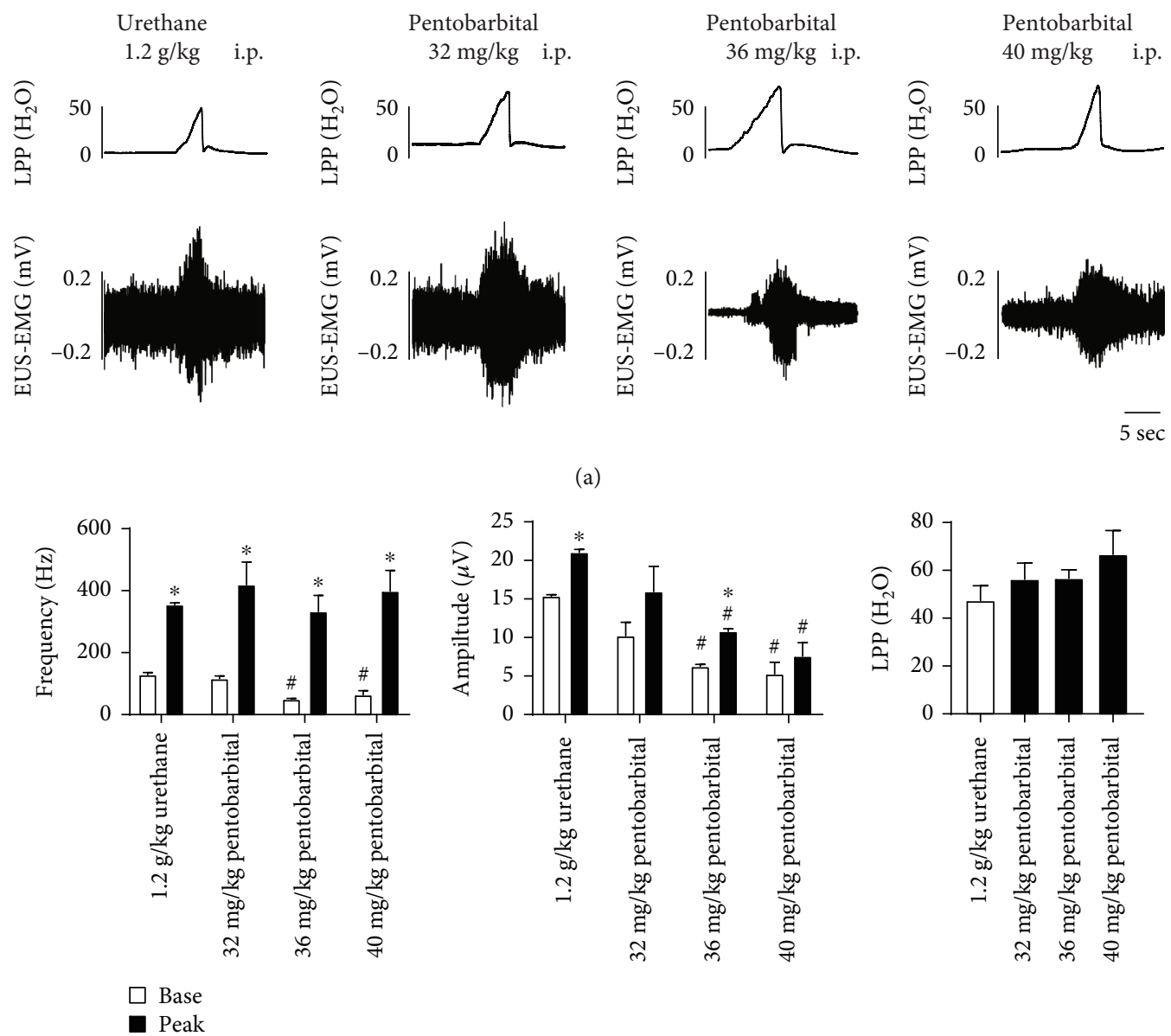

(b)

FIGURE 5: LPP and EUS-EMG results under anesthesia with urethane and different dosages of pentobarbital. Data reported as the mean \pm SEM. Representative examples of EUS-EMG activity indifferent anesthesia groups (a). Top, LPP; bottom, EUS-EMG activity during LPP. * indicates a statistically significant difference compared to data at baseline in the same group. \# indicates a statistically significant difference compared to rats that had anesthesia with urethane $(p<0.05)$. LPP: leak point pressure; EUS-EMG: external urethral sphincter electromyography; i.p.: intraperitoneal injection.

present study, compared with urethane anesthesia, LPP was not significantly different after anesthesia with $40 \mathrm{mg} / \mathrm{kg}$, $36 \mathrm{mg} / \mathrm{kg}$, and $32 \mathrm{mg} / \mathrm{kg}$ sodium pentobarbital.

\section{Study Limitations}

Although this study found that micturition was not suppressed when rats are anesthetized with low-dose sodium pentobarbital, the present study has several limitations. First, the study groups do not include a lower dosage of pentobarbital than $32 \mathrm{mg} / \mathrm{kg}$, due to the fact that the animal could not get quite sufficient when the dosage of pentobarbital decreased lower than $32 \mathrm{mg} / \mathrm{kg}$. Second, the mechanism of pentobarbital sodium on micturition reflex has not been studied, mainly hampered by our knowledge scope and lab facilities, for example, pharmacological study and signaling transduction of $\mathrm{GABA}_{\mathrm{A}}$ receptor channels. Third, our study only observed the effect of pentobarbital sodium on micturition in female rats, and the dose-dependent effects of pentobarbital on lower urinary tract function in other species need to be investigated in the future. Fourth, we used urethane as an anesthetic agent for the urodynamic study in the control group; it may be more convincing had the sodium pentobarbital group be compared with the urodynamic data in the awake animals.

\section{Conclusions}

Pentobarbital was used to be considered to have obvious influence on lower urinary tract function. Thus, pentobarbital is not recommended for urodynamic experiments under a previous protocol. In the present study, we established a survival model for examining external urethral sphincter electromyography simultaneously during testing cystometry and leak point pressure tests by means of defining the dosagedependent effects of pentobarbital on the lower urinary tract function and provide a nonurethane protocol, a suitable and practicable dosage of pentobarbital anesthesia in recovery urodynamic experiments with female rats. We found that high pentobarbital doses remarkably suppress lower urinary tract function, with impaired bladder contractions and EUSEMG activation. Under a critical low-dose pentobarbital 
anesthesia, the lower urinary tract function is less affected, with analogous bladder contraction and EUS-EMG activation patterns comparable with that of urethane anesthesia.

In summary, this study confirmed significant dosedependent effects of pentobarbital on lower urinary tract function and $32 \mathrm{mg} / \mathrm{kg}$ pentobarbital as an appropriate dosage for recovery urodynamic testing, which enable the achievement of expected essential micturition under satisfactory anesthesia in female rats.

\section{Data Availability}

The data used to support the findings of this study are included within the article.

\section{Disclosure}

The funder had no role in the study design, data collection and analysis, decision to publish, or preparation of the manuscript.

\section{Conflicts of Interest}

The authors declared that they have no conflicts of interest to this work.

\section{Authors' Contributions}

Sheng-fei $\mathrm{Xu}$ and Guang-hui Du performed experiment and wrote the paper. Kuerbanjiang Abulikim and Peng Cao performed the research and analyzed the data. Hui-bing Tan analyzed the data.

\section{Acknowledgments}

This study was supported by the National Natural Science Foundation of China (nos. 81800673 and 30772290).

\section{References}

[1] B. K. LaPallo, J. R. Wolpaw, X. Y. Chen, and J. S. Carp, "Contribution of the external urethral sphincter to urinary void size in unanesthetized unrestrained rats," Neurourology and Urodynamics, vol. 35, no. 6, pp. 696-702, 2016.

[2] M. P. Schneider, F. M. Hughes Jr., A. K. Engmann et al., "A novel urodynamic model for lower urinary tract assessment in awake rats," BJU International, vol. 115, Suppl 6, pp. 8-15, 2015.

[3] T. Kitta, T. Mitsui, Y. Kanno et al., "Differences in neurotransmitter systems of ventrolateral periaqueductal gray between the micturition reflex and nociceptive regulation: an in vivo microdialysis study," International Journal of Urology, vol. 23, no. 7, pp. 593-598, 2016.

[4] S. Matsuura and J. W. Downie, "Effect of anesthetics on reflex micturition in the chronic cannula-implanted rat," Neurourology and Urodynamics, vol. 19, no. 1, pp. 87-99, 2000.

[5] C. A. Maggi and A. Meli, "Suitability of urethane anesthesia for physiopharmacological investigations. Part 3: other systems and conclusions," Experientia, vol. 42, no. 5, pp. 531-537, 1986.
[6] R. J. Mason, M. Kalina, L. D. Nielsen, A. M. Malkinson, and J. M. Shannon, "Surfactant protein C expression in urethaneinduced murine pulmonary tumors," The American Journal of Pathology, vol. 156, no. 1, pp. 175-182, 2000.

[7] A. M. Malkinson and D. S. Beer, "Major effect on susceptibility to urethan-induced pulmonary adenoma by a single gene in BALB/cBy mice," Journal of the National Cancer Institute, vol. 70, no. 5, pp. 931-936, 1983.

[8] D. G. Beer and A. M. Malkinson, "Genetic influence on type 2 or Clara cell origin of pulmonary adenomas in urethan-treated mice," Journal of the National Cancer Institute, vol. 75, no. 5, pp. 963-969, 1985.

[9] P. Aronsson, T. Carlsson, M. Winder, and G. Tobin, "A novel in situ urinary bladder model for studying afferent and efferent mechanisms in the micturition reflex in the rat," Neurourology and Urodynamics, vol. 33, no. 5, pp. 550-557, 2014.

[10] J. L. Tremoleda, A. Kerton, and W. Gsell, "Anaesthesia and physiological monitoring during in vivo imaging of laboratory rodents: considerations on experimental outcomes and animal welfare," EJNMMI Research, vol. 2, no. 1, pp. 44-44, 2012.

[11] F. J. Sierra-Valdez, J. C. Ruiz-Suarez, and I. Delint-Ramirez, "Pentobarbital modifies the lipid raft-protein interaction: a first clue about the anesthesia mechanism on NMDA and GABA A receptors," Biochimica et Biophysica Acta, vol. 1858, no. 11, pp. 2603-2610, 2016.

[12] T. L. Yaksh, P. A. Durant, and C. R. Brent, "Micturition in rats: a chronic model for study of bladder function and effect of anesthetics," The American Journal of Physiology, vol. 251, 6 Part 2, pp. R1177-R1185, 1986.

[13] H. Yanai-Inamura, R. Ohashi, T. Ishigami et al., "Urethral function and histopathology in aged female rats as a stress urinary incontinence model," LUTS: Lower Urinary Tract Symptoms, vol. 11, no. 2, pp. O186-O192, 2018.

[14] T. Y. Mariano, N. Bhadra, and K. J. Gustafson, "Suppression of reflex urethral responses by sacral dermatome stimulation in an acute spinalized feline model," Neurourology and Urodynamics, vol. 29, no. 3, pp. 494-500, 2010.

[15] A. Ohtake, S. Sato, M. Sasamata, and K. Miyata, "Effects of tamsulosin on resting urethral pressure and arterial blood pressure in anaesthetized female dogs," The Journal of Pharmacy and Pharmacology, vol. 58, no. 3, pp. 345-350, 2006.

[16] K. Sudoh, H. Tanaka, O. Inagaki, M. Asano, and T. Takenaka, "Effect of tamsulosin, a novel alpha 1-adrenoceptor antagonist, on urethral pressure profile in anaesthetized dogs," Journal of Autonomic Pharmacology, vol. 16, no. 3, pp. 147-154, 1996.

[17] S. Xu, X. Li, L. Xu, B. Chen, H. Tan, and G. du, "A method for recording urethral pressure profiles in female rats," PLoS One, vol. 10, no. 10, article e0140851, 2015.

[18] S. Kanie, A. Otsuka, S. Yoshikawa et al., "TRK-380, a Novel Selective Human $\beta_{3}$-Adrenoceptor Agonist, Ameliorates Formalin-induced Pollakiuria in Rats and Carbachol- induced Bladder Contraction in Dogs," Urology, vol. 82, no. 4, pp. 975.e7-975.e12, 2013.

[19] P. Satchell and C. Vaughan, "Efferent pelvic nerve activity, ganglionic filtering, and the feline bladder," American Journal of Physiology-Regulatory, Integrative and Comparative Physiology, vol. 256, no. 6, pp. R1269-R1273, 1989.

[20] M. Nitta, T. Tamaki, K. Tono et al., "Reconstitution of experimental neurogenic bladder dysfunction using skeletal muscle-derived multipotent stem cells," Transplantation, vol. 89, no. 9, pp. 1043-1049, 2010. 
[21] C. Qin, J. P. Farber, and R. D. Foreman, "Spinal cord stimulation modulates activity of lumbosacral spinal neurons receiving input from urinary bladder in rats," Neuroscience Letters, vol. 428, no. 1, pp. 38-42, 2007.

[22] T. Obara, S. Matsuura, S. Narita, S. Satoh, N. Tsuchiya, and T. Habuchi, "Bladder acellular matrix grafting regenerates urinary bladder in the spinal cord injury rat," Urology, vol. 68, no. 4, pp. 892-897, 2006.

[23] C. Qin, A. P. Malykhina, H. I. Akbarali, and R. D. Foreman, "Cross-organ sensitization of lumbosacral spinal neurons receiving urinary bladder input in rats with inflamed colon," Gastroenterology, vol. 129, no. 6, pp. 1967-1978, 2005.

[24] S. Palea, P. Lluel, M. Barras, C. Duquenne, A. M. Galzin, and S. Arbilla, "Involvement of 5-hydroxytryptamine (HT)7 receptors in the 5-HT excitatory effects on the rat urinary bladder," BJU International, vol. 94, no. 7, pp. 1125-1131, 2004.

[25] K. Sudoh, N. Masuda, and W. Uchida, "Different effect of anticholinergic agents and potassium channel openers on urinary bladder response to pelvic nerve stimulation in anaesthetized dogs," Journal of Autonomic Pharmacology, vol. 17, no. 2, pp. 91-96, 1997.

[26] N. Bhadra, V. Grünewald, G. Creasey, and J. T. Mortimer, "Selective suppression of sphincter activation during sacral anterior nerve root stimulation," Neurourology and Urodynamics, vol. 21, no. 1, pp. 55-64, 2002.

[27] P. Aronsson, T. Carlsson, M. Winder, and G. Tobin, "Cyclophosphamide-induced alterations of the micturition reflex in a novel in situ urinary bladder model in the anesthetized rat," Neurourology and Urodynamics, vol. 34, no. 4, pp. 375380, 2015.

[28] Z. Xiong, Y. Wang, W. Gong, Z. Zhou, and G. Lu, "Expression of Hsp27 correlated with rat detrusor contraction after acute urinary retention," Molecular and Cellular Biochemistry, vol. 381, no. 1-2, pp. 257-265, 2013.

[29] A. Malmgren, C. Sjögren, B. Uvelius, A. Mattiasson, K. E. Andersson, and P. O. Andersson, "Cystometrical evaluation of bladder instability in rats with infravesical outflow obstruction," The Journal of Urology, vol. 137, no. 6, pp. 1291-1294, 1987.

[30] K. E. Andersson, R. Soler, and C. Füllhase, "Rodent models for urodynamic investigation," Neurourology and Urodynamics, vol. 30, no. 5, pp. 636-646, 2011.

[31] L. R. Soma, "Anesthetic and analgesic considerations in the experimental animal," Annals of the New York Academy of Sciences, vol. 406, no. 1 The Role of A, pp. 32-47, 1983.

[32] W. J. White and K. J. Field, "Anesthesia and surgery of laboratory animals," The Veterinary Clinics of North America. Small Animal Practice, vol. 17, no. 5, pp. 989-1017, 1987.

[33] S. Chiba and M. Tsuboi, "Dominant anti-vagal effect of pentobarbital on cardiac responses to intracardiac autonomic nerve stimulation in the dog," Japanese Journal of Pharmacology, vol. 86, no. 2, pp. 248-250, 2001.

[34] M. Eikermann, P. Fassbender, S. Zaremba et al., "Pentobarbital dose-dependently increases respiratory genioglossus muscle activity while impairing diaphragmatic function in anesthetized rats," Anesthesiology, vol. 110, no. 6, pp. 1327-1334, 2009.

[35] Y. Igawa, A. Mattiasson, and K. E. Andersson, "Effects of GABA-receptor stimulation and blockade on micturition in normal rats and rats with bladder outflow obstruction," The Journal of Urology, vol. 150, 2 Part 1, pp. 537-542, 1993.
[36] H. H. Jiang, H. Q. Pan, M. A. Gustilo-Ashby et al., "Dual simulated childbirth injuries result in slowed recovery of pudendal nerve and urethral function," Neurourology and Urodynamics, vol. 28, no. 3, pp. 229-235, 2009.

[37] F. Z. Laalou, A. P. de Vasconcelos, P. Oberling, H. Jeltsch, J. C. Cassel, and L. Pain, "Involvement of the basal cholinergic forebrain in the mediation of general (propofol) anesthesia," Anesthesiology, vol. 108, no. 5, pp. 888-896, 2008.

[38] A. A. Moheban, H. H. Chang, and L. A. Havton, "The suitability of propofol compared with urethane for anesthesia during urodynamic studies in rats," Journal of the American Association for Laboratory Animal Science, vol. 55, no. 1, pp. 89-94, 2016.

[39] H. Y. Chang and L. A. Havton, "Differential effects of urethane and isoflurane on external urethral sphincter electromyography and cystometry in rats," American Journal of Physiology. Renal Physiology, vol. 295, no. 4, pp. F1248-F1253, 2008.

[40] Y. Cruz, C. Pastelín, B. M. Balog, P. J. Zaszczurynski, and M. S. Damaser, "Somatomotor and sensory urethral control of micturition in female rats," American Journal of Physiology. Renal Physiology, vol. 307, no. 11, pp. F1207-F1214, 2014.

[41] M. S. Damaser, F. J. Kim, and G. M. Minetti, "Methods of testing urethral resistance in the female rat," Advances in Experimental Medicine and Biology, vol. 539, no. Part B, pp. 831-839, 2003.

[42] R. L. MacDonald, C. J. Rogers, and R. E. Twyman, "Barbiturate regulation of kinetic properties of the GABAA receptor channel of mouse spinal neurones in culture," The Journal of Physiology, vol. 417, no. 1, pp. 483-500, 1989.

[43] T. W. Cannon and M. S. Damaser, "Effects of anesthesia on cystometry and leak point pressure of the female rat," Life Sciences, vol. 69, no. 10, pp. 1193-1202, 2001.

[44] M. N. Kruse, A. L. Belton, and W. C. de Groat, "Changes in bladder and external urethral sphincter function after spinal cord injury in the rat," The American Journal of Physiology, vol. 264, 6 Part 2, pp. R1157-R1163, 1993.

[45] H. H. Chang, J. C. Yeh, R. M. Ichiyama, L. V. Rodriguez, and L. A. Havton, "Mapping and neuromodulation of lower urinary tract function using spinal cord stimulation in female rats," Experimental Neurology, vol. 305, pp. 26-32, 2018.

[46] I. Kamo, T. W. Cannon, D. A. Conway et al., "The role of bladder-to-urethral reflexes in urinary continence mechanisms in rats," American Journal of Physiology-Renal Physiology, vol. 287, no. 3, pp. F434-F441, 2004. 